\title{
Pharmacy Support of a Pediatric Patient Receiving Milrinone at Home
}

\author{
Ariel Xue, Deonne Dersch-Mills, Clara Tsang, and Steven C Greenway
}

\section{INTRODUCTION}

$\mathrm{H}^{\infty}$ eart failure in children is a progressive clinical syndrome characterized by symptoms that may include respiratory distress, poor growth, edema, fatigue, feeding difficulties, and exercise intolerance. ${ }^{1,2}$ The predominant causes of pediatric heart failure in developed countries are cardiomyopathy (including the dilated, hypertrophic, and restrictive cardiomyopathies) and congenital heart disease. ${ }^{2,3}$ As heart failure progresses in severity, the child experiences worsening of symptoms and increasing frequency of exacerbations, emergency department visits, and hospital admissions. ${ }^{4}$ In end-stage heart failure, the symptoms become refractory to oral medications, and the child becomes dependent on IV therapies. ${ }^{4}$ For children who are eligible for cardiac transplant, bridging therapy with a continuous inotropic infusion (to maintain end-organ perfusion) is often required while awaiting a suitable organ. ${ }^{4}$ For those who are ineligible for transplant, a continuous inotropic infusion may be used as palliative therapy. ${ }^{5}$

Milrinone, a potent inhibitor of phosphodiesterase type III, stimulates cardiac function independently of $ß$-adrenergic receptors. It improves cardiac output via its positive inotropic effects with little chronotropic effect, and it reduces afterload by concomitant vasodilation. ${ }^{6,7}$ Milrinone is also an effective lusitropic agent and augments ventricular diastolic relaxation in addition to systolic contractility. ${ }^{7}$ As a result, milrinone has become the first-line therapy for infants and children with heart failure to prevent low cardiac output syndrome after cardiac surgery. ${ }^{3,6,7}$
The concept of outpatient inotropic therapy has been around for several decades, and there are multiple reports of patients with heart failure being managed at home on a continuous infusion of milrinone (see Table 1). ${ }^{4,5}$ Alberta Children's Hospital is a freestanding pediatric facility in Calgary, Alberta, with about 140 acute care beds. Each year, 1-3 children with end-stage heart failure who are being followed in the hospital's Cardiology Clinic are listed for heart transplant (with the surgery being performed in Edmonton, Alberta); therapies for these children may include multiple oral medications and IV milrinone. Alberta Children's Hospital began offering home milrinone therapy to patients in 2013 according to the criteria listed in Box 1.

The benefits of home milrinone therapy are numerous, including reductions in emergency department visits and hospital admissions for cardiac indications, and improvements in estimated ejection fraction. ${ }^{4,5}$ Perhaps most importantly, home milrinone therapy also improves quality of life by allowing children to resume a modified normal lifestyle (which may include return to school), by supporting improvements in psychosocial health, and by reducing parenteral and family stress. ${ }^{5}$ Finally, home milrinone therapy carries a significant financial advantage for health care systems. According to Berg and others, ${ }^{5}$ the total daily cost (in 2005 US dollars) of inotropic therapy for a pediatric patient awaiting heart transplant was $\$ 745$ as a hospital inpatient and \$134 for home therapy.

Despite the numerous benefits that home milrinone therapy offers, there are also potential risks. This medication can cause

Table 1. Summary of Previous Literature on Home Milrinone Therapy in Pediatric Patients

\begin{tabular}{lcrcc} 
Year of Publication & Study & No. of patients & $\begin{array}{c}\text { Dose of Milrinone by Infusion } \\
(\boldsymbol{\mu} \mathbf{g} / \mathbf{k g} \text { per minute) }\end{array}$ & $\begin{array}{c}\text { Mean Duration of Home } \\
\text { Milrinone Therapy (Range) }\end{array}$ \\
\hline 2005 & Price et al. ${ }^{4}$ & 6 & $0.25 \pm 0.03$ (mean \pm SD) & 155 days (27-588 days) \\
2007 & Berg et al. $^{5}$ & 11 & $0.5-1.0$ (range) & 68 days (14-476 days) \\
2016 & Present case & 1 & $0.5-0.75$ (range) & About 420 days (14 months) \\
\hline
\end{tabular}

$\mathrm{SD}=$ standard deviation. 


\author{
Box 1. Criteria of the Alberta Children's Hospital for Milrinone Therapy on the Ward and at Home* \\ Patient criteria for ward milrinone \\ - Stable HR and BP on milrinone $>2$ days in PICU (initiation of therapy) \\ - inotrope-dependent or prolonged therapy anticipated \\ no recent changes in milrinone dosage or cardiac medications \\ - Patient admitted from home electively for "tune-up" or dose increase in stable patient \\ - Patient listed for cardiac transplantation \\ - Milrinone $\leq 0.75 \mathrm{mcg} / \mathrm{kg} / \mathrm{min}$ \\ - Stable venous access (PICC, CVL) \\ - Does not require continuous ECG monitoring \\ - 2:1 patient:RN ratio with admission to bed in monitored yellow hallway on Unit 2 \\ - Mandatory STEP consult (either education consult or complete activation) \\ - Hospital paediatrician consult (if patient admitted under Cardiology)
}

\title{
Patient criteria for home milrinone
}

Ward criteria plus:

- Stable central venous access (tunneled CVL, PICC)

- Stable HR and BP for 4 days prior to discharge

- Stable on current medications (not requiring frequent dose changes)

- Age $>1$ year

- older patient if more remote location

- Adequate family support

- Family/patient willing and capable of care for line, medication administration and pump

- daily heparin lock

- medication bag and tubing change every 48 hours

- Home nursing support available

- weekly dressing and cap changes

- vital signs as needed

patient weights as needed

- Telephone access

- Within 1 hour of local medical centre

- Weekly visit to ACH Cardiology clinic

- Patient/family taught signs/symptoms of worsening HF

- follow daily TFI

$\mathrm{ACH}=$ Alberta Children's Hospital; $\mathrm{BP}=$ blood pressure; $\mathrm{CVL}=$ central venous line; $\mathrm{ECG}=$ electrocardiography; $\mathrm{HF}=$ heart failure; $\mathrm{HR}=$ heart rate; $\mathrm{mcg}=$ microgram $(\mu \mathrm{g}) ; \mathrm{PICC}=$ peripherally inserted central catheter; $\mathrm{PICU}=$ pediatric intensive care unit; $\mathrm{RN}=$ registered nurse; STEP = specialized, transitional, educational, personal (a critical care outreach team responsible for transition management of PICU patients to inpatient units); TFI = total fluid intake; Unit 2 = non-intensive care ward at ACH. *Reproduced, with permission, from Milrinone Guideline [internal institutional guideline]. (c) 2013 Alberta Children's Hospital.

hypotension, thrombocytopenia, and ventricular arrhythmias, with the latter 2 conditions being rare in children and neonates. ${ }^{8}$ Although hypotension may be more likely to develop at initiation and with dose increases, the adverse effects can occur at any time during therapy. ${ }^{8}$ Price and others ${ }^{4}$ reported one death due to ventricular arrhythmia in a patient with a pre-existing history of nonsustained ventricular tachycardia who received milrinone. The risk of ventricular arrhythmias with long-term milrinone therapy may be highest in patients with a history of arrhythmia, but this risk can be minimized by placement of an implantable cardioverter defibrillator before initiation of home milrinone, provided the risk of ventricular arrhythmia is thought to outweigh the risks associated with implantation of the device. ${ }^{4}$ Furthermore, the risks of potential drug-related adverse events can be reduced by setting stringent selection criteria for home milrinone therapy (see Box 1). Other complications of home milrinone therapy are associated with IV line infection, occlusion, or extravasation. Price and others ${ }^{4}$ reported that only 2 of 7 patients experienced catheter-related complications (infection, repeated partial extravasation). In the case series by Berg and others, 5 of 26 hospital readmissions were due to catheter infections, whereas 15 of the 26 were due to decompensation of heart failure. Two of these decompensation episodes were related to the patient's mismanagement of the pump at home. ${ }^{5}$

In Canada, pediatric and adult patients maintained on multiple or high-dose inotropes are assigned a high priority for transplant. This therapeutic approach allows the candidates to remain in a higher-priority group without necessarily having to stay in hospital, which in turn has led to the emergence of home parenteral inotropic therapy. According to the 2016 annual report of the Canadian Organ Replacement Register, the number of children younger than 18 years waiting for a heart transplant increased from 9 in 2005 to 18 in $2014 .{ }^{9}$ With longer waiting lists and wait times to heart transplant, there is an increasing demand for long-term inotropic support as bridging therapy. Alternatively, children who are ineligible for transplant because of comorbidities or family preference also 
require long-term inotropic therapy to relieve symptoms in the palliative setting. ${ }^{5}$ In addition, lack of capacity in the pediatric intensive care unit (PICU) frequently necessitates strategies to create a "shuffling effect"-moving patients into non-ICU wards and eventually discharging them home. At the authors' site, pediatric patients listed for heart transplant who have been stabilized on milrinone therapy for more than 2 days in the PICU (at $\leq 0.75 \mu \mathrm{g} / \mathrm{kg}$ per minute) can potentially be transferred to non-ICU wards with close monitoring (Box 1). Subsequently, stable patients who have adequate family support are potentially eligible for home milrinone therapy (Box 1), which enables early discharge from the hospital, thereby reducing patient load on non-ICU wards and alleviating congestion in the PICU.

\section{CASE REPORT}

Here we describe the first case from our centre of a pediatric patient who was bridged to heart transplant by means of home milrinone therapy.* Although several Canadian pediatric hospitals may be adopting or may already have similar milrinone programs, this is the first published report of successful pediatric home milrinone therapy from a Canadian pharmacy perspective. This report highlights the contribution of the pharmacy team in the transition process.

Complete atrioventricular septal defect was diagnosed in a 1-month-old infant. Repair of this defect was complicated by residual left atrioventricular valvar regurgitation and complete heart block requiring mechanical valve replacement and then insertion of a permanent pacemaker. Several months later, the patient developed severe biventricular dysfunction (left ventricular ejection fraction of $24 \%$, normally $>53 \%$ ) related to coronary sinus thrombosis. Because there was extensive ventricular fibrosis (as shown by cardiac magnetic resonance imaging) and no possibility of functional recovery, the patient was listed for heart transplant. During the first 1.5 years while awaiting transplant, the patient had 3 separate admissions to the PICU for brief (3-5 days) intermittent infusions of milrinone $(0.5 \mu \mathrm{g} / \mathrm{kg}$ per minute). Eventually, the patient was admitted because of progression of the heart failure symptoms; continuous milrinone infusion was required, initially at $0.25 \mu \mathrm{g} / \mathrm{kg}$ per minute and subsequently increased to $0.5 \mu \mathrm{g} / \mathrm{kg}$ per minute.

After receiving a continuous milrinone infusion for more than a month, the patient was transitioned to home milrinone therapy (by pump) in consultation with the home parenteral therapy program (HPTP). At that time, the patient was 3 years, 11 months of age and weighed $17 \mathrm{~kg}$. The HPTP at Alberta Children's Hospital is typically responsible for the administration of prolonged antibiotic therapy at home. Given the similar logistics and requirements for home administration of milrinone, it was thought that the HPTP was the best program to access,

\footnotetext{
*The patient's family gave consent for publication of this case report.
}

rather than creating an entirely new program. Nonetheless, the use of milrinone in the home setting required extensive education and logistical planning within the HPTP. As a result of the collaborative effort of home care nursing, social work, pharmacy, cardiology, and the HPTP clinic, the patient was eventually discharged home on a continuous milrinone infusion at $0.5 \mu \mathrm{g} / \mathrm{kg}$ per minute. Because this patient was the first from this site to go home while receiving milrinone by infusion, there was a several-week delay to discharge while the logistics of home milrinone therapy were developed. We anticipate that these delays will be significantly reduced for future patients.

After 7 months on home milrinone therapy, the patient experienced worsening heart failure and was admitted to the PICU with significant lethargy and increased $\mathrm{N}$-terminal pro brain natriuretic peptide (NT-proBNP). The milrinone dose was increased to $0.75 \mu \mathrm{g} / \mathrm{kg}$ per minute, and the patient was again discharged home. Another 6 months later, the heart failure had progressed further, and there were signs of end-organ dysfunction. The milrinone dose was maximized at $0.99 \mu \mathrm{g} / \mathrm{kg}$ per minute. A left ventricular assist device (HeartWare HVAD, Framingham, Massachusetts) was subsequently inserted, and the milrinone was discontinued after a total of 14 months of therapy. The patient was dependent on the left ventricular assist device for 5.5 months and eventually received a heart transplant after waiting a total of 3 years and 2 months.

The HPTP typically estimates cost savings on the basis of an average cost of CAN $\$ 1860$ per patient-day of admission. Although this estimate is not pediatric- or case-specific, it suggests an approximate cost savings associated with the home milrinone therapy of about $\$ 781000$.

While supported with milrinone at home, the patient was able to enjoy a good quality of life; the patient was able to travel to amusement parks, go camping, and visit family outside of Calgary. The patient grew into a rambunctious child, and the peripherally inserted central catheter fractured 4 times; line rewiring was required on one occasion and line replacements the other 3 times. There had been several line infections during initial milrinone therapy in hospital, a problem that was resolved with decreased frequency of dressing changes (i.e., the dressing was changed only when visibly soiled or detached). With careful management, there were no line infections or thromboses during the home milrinone therapy. Of note, no heparin was added to the line or used in flushes.

\section{BARRIERS TO HOME MILRINONE THERAPY AND THEIR RESOLUTION}

This patient was the first at Alberta Children's Hospital to go home while receiving milrinone by infusion. As such, the transition involved extensive planning (see Table 2). Several pharmacy-specific logistical challenges were encountered, the first being a manufacturer shortage of milrinone, which meant that 
This single copy is for your personal, non-commercial use only.

For permission to reprint multiple copies or to order presentation-ready copies for distribution, contact CJHP at cjhpedit@cshp.ca

Table 2. Logistical Challenges and Roles of Pharmacy Team in Supporting Home Milrinone Therapy

\begin{tabular}{lll} 
Logistical Challenge & \multicolumn{1}{c}{ Personnel Involved } & \multicolumn{1}{c}{ Role of Pharmacy Team } \\
\hline Supply of medication during shortage & $\begin{array}{l}\text { Inpatient and outpatient pharmacy } \\
\text { purchasing staff }\end{array}$ & $\begin{array}{l}\text { Arranging purchase of milrinone for } \\
\text { outpatient use }\end{array}$ \\
\hline Medication solution: recipes & $\begin{array}{l}\text { HPTP pharmacist, drug information } \\
\text { pharmacist }\end{array}$ & $\begin{array}{l}\text { Creation of evidence-supported recipe } \\
\text { with appropriate stability }\end{array}$ \\
\hline Medication solution: costs & HPTP pharmacist, social worker & $\begin{array}{l}\text { Use of a recipe that minimized waste; } \\
\text { provision of estimated costs for coverage } \\
\text { application }\end{array}$ \\
\hline Manufacture and supply of IV solutions & Outpatient pharmacy & $\begin{array}{l}\text { Provision of timely and appropriately } \\
\text { prepared IV solutions }\end{array}$ \\
\hline V supply costs & HPTP nurses, outpatient pharmacy staff, & $\begin{array}{l}\text { Provision of supplies; permitting "credit" } \\
\text { while awaiting insurance coverage }\end{array}$ \\
\hline Infusion pump access and programming & HPTP clinic staff, HPTP pharmacist & $\begin{array}{l}\text { Communication of dose changes and/or } \\
\text { pump programming }\end{array}$ \\
\hline Care and maintenance of central line & HPTP nurse, home care nurses, family & $\begin{array}{l}\text { Potential involvement in decision-making } \\
\text { related to flush/lock solutions or antibiotic } \\
\text { use (as needed) }\end{array}$ \\
\hline Patient monitoring at home & & $\begin{array}{l}\text { Potential advisory role regarding adverse } \\
\text { effects of medications (as needed) }\end{array}$ \\
\hline Family education & HPTP clinic nurses, Cardiology Clinic nurses, \\
& home care nurses, family & $\begin{array}{l}\text { Teaching about medication-related } \\
\text { monitoring parameters (in conjunction } \\
\text { with rest of team) }\end{array}$ \\
\hline HPTP = home parenteral therapy program
\end{tabular}

HPTP = home parenteral therapy program .

only the inpatient pharmacy department could obtain the drug. Arrangements were made for the inpatient pharmacy to supply milrinone to the outpatient pharmacy, which then provided the drug to the HPTP for the patient. The patient also needed a home IV pump, but the HPTP pumps had been purchased for use only in the infectious diseases clinic. After exploration of various options with the cardiology team, it was decided that the best approach would be to have the Infectious Diseases Clinic lend the family a pump (Hospira GemStar Infusion System, Hospira, Inc, Lake Forest, Illinois). The same pump was used for the entire duration of home milrinone therapy. The HPTP nurse clinician also prepared a back-up pump of the same model, which was loaned to the family in case of pump failure.

Next, a milrinone solution with appropriate concentration and stability for the home IV pump was needed. The HPTP clinic pharmacist designed a recipe for this solution that allowed the outpatient pharmacy to prepare the milrinone on a weekly basis, in batches of 10 bags, to reduce waste. The parents were able to pick up the milrinone and the IV supplies once a week from the outpatient pharmacy. The milrinone was stored in the refrigerator in the patient's home with no adverse events.

During the week before discharge, the home milrinone therapy was trialled on brief (24-48 h) home passes, using bags containing sufficient milrinone for a 48 -h period. However, the HPTP nurse clinician thought that the line was difficult to flush after $48 \mathrm{~h}$ and suggested daily bag changes and line flushes to help preserve the line $(5-\mathrm{mL}$ slow flush, $10-\mathrm{mL}$ turbulent flush with normal saline). Upon discharge, the patient was receiving milrinone infusion at $0.5 \mu \mathrm{g} / \mathrm{kg}$ per minute $(100 \mu \mathrm{g} / \mathrm{mL}$ solution at a rate of $5 \mathrm{~mL} / \mathrm{h}) .{ }^{10}$ When subsequent dose increases were required, the HPTP pharmacist considered the family's familiarity with the original $5 \mathrm{~mL} / \mathrm{h}$ infusion rate and the convenience of not having to reprogram the pump, and decided to increase the concentration of the milrinone solution. With each dose change, a new compounding worksheet was created, with double checks, as per pharmacy policies. ${ }^{10}$ The infusion rates throughout milrinone use were as follows: $0.5 \mu \mathrm{g} / \mathrm{kg}$ per minute (with a $100 \mu \mathrm{g} / \mathrm{mL}$ solution) for about 7 months, $0.75 \mu \mathrm{g} / \mathrm{kg}$ per minute (with a $164 \mu \mathrm{g} / \mathrm{mL}$ solution) for about 6 months, and $0.99 \mu \mathrm{g} / \mathrm{kg}$ per minute (with a $210 \mu \mathrm{g} / \mathrm{mL}$ solution) for about 1 month. Although less complicated for the family, this strategy placed an extra burden on the pharmacy team and was very timeconsuming. Keeping the infusion rate constant resulted in the need to prepare solutions with concentrations that involved difficult measurements and calculations. In addition, new stability information was required every time since, for reasonable home administration, the drug had to be stable for at least 3 days to avoid frequent trips to the outpatient pharmacy. In hindsight, maintaining a constant concentration and adjusting the rate would have been a more practical solution. Of note, dosage changes were made only on the basis of the patient's clinical condition; the dose was never adjusted for growth alone, although a revised weight was used with each dosage adjustment for clinical purposes.

Another barrier to sending the patient home was arranging payment for the milrinone. Social work support through the Cardiology Clinic played an important role in securing a social services plan for 1 year, with $100 \%$ coverage of the medication. The outpatient pharmacy was able to directly bill this plan for the medication. After this plan expired, the care team and family applied for special authorization coverage for the milrinone, which was granted by the family's existing insurer. While awaiting 
this special authorization, the family picked up the drug from the outpatient pharmacy with written promissory notes. The average weekly cost of IV supplies (paid for by the family) was between $\$ 15$ and $\$ 25$. Significant work went into securing financial assistance for this family, and this aspect would certainly be a challenge for any future patients.

Another important hurdle in setting up home milrinone therapy was ensuring adequate family education. When the HPTP clinic initially assessed the family, the mother demonstrated capability to manage line care, medication administration, and pump care. She was able to assess her child's clinical symptoms and knew when to seek medical help. The family was very willing to learn the processes necessary to administer milrinone therapy at home. Despite the fact that home milrinone therapy had never been done through the HPTP clinic, the patient's supportive family served as a strong motivator for implementation of this new initiative. Before discharge, the family was given an individualized home care plan that detailed the required care activities, monitoring parameters, and followup times. Cardiology nurses focused on teaching the family about the clinical signs and symptoms of heart failure and infection. The HPTP nurse clinician gave the family instructions for daily line and pump care, as well as information about how to change the tubing and pump battery every 3 days. The family was also informed about what to do if the pump or line failed and was given a list of supplies to be ordered weekly from the outpatient pharmacy. Parental comfort with the entire process was crucial for success, and not every family would be able and willing to assume the degree of responsibility required to support the use of milrinone at home.

A home care nurse monitored the patient daily for the first week after discharge and then twice weekly thereafter. The home care nurse assisted the family with line and pump care and also assessed vital signs and symptoms of heart failure and/or infection. The cardiologist saw the patient weekly in clinic, and the family also had access to after-hours, on-call home care nursing support and on-call cardiologist support. The HPTP nurse clinician continued to support the family as well. Regular contact with the care team was essential to the success of this case.

\section{CONCLUSION}

Continuous milrinone infusion is a life-saving therapy for infants and children who are awaiting heart transplant. Home milrinone therapy offers multiple benefits for the children and their families, as well as cost savings and capacity relief for hospitals. Although home milrinone therapy carries rare but important risks, these can be minimized through extensive family training, close follow-up, and excellent communication. The pharmacy department, as part of the collaborative, multidisciplinary team, has an important role in supporting home milrinone therapy by infusion. For the patient described here, the pharmacy team played a key role in solving the logistical challenges associated with taking a medication that had previously been used only in the ICU and moving the therapy into the outpatient setting.

\section{References}

1. Hsu DT, Pearson GD. Heart failure in children: part I: history, etiology, and pathophysiology. Circ Heart Fail. 2009;2(1):63-70.

2. Kirk R, Dipchand AI, Rosenthal DN, Addonizio L, Burch M, Chrisant $\mathrm{M}$, et al. The International Society of Heart and Lung Transplantation guidelines for the management of pediatric heart failure: executive summary. J Heart Lung Transplant. 2014;33(9):888-909.

3. Kantor PF, Lougheed J, Dancea A, McGillion M, Barbosa N, Chan C, et al. Presentation, diagnosis, and medical management of heart failure in children: Canadian Cardiovascular Society guidelines. Can J Cardiol. 2013;29(12):1535-52.

4. Price JF, Towbin JA, Dreyer WJ, Moffett BS, Kertesz NJ, Clunie SK, et al. Outpatient continuous parenteral inotropic therapy as bridge to transplantation in children with advanced heart failure. J Card Fail. 2006; 12(2):139-43.

5. Berg AM, Snell L, Mahle WT. Home inotropic therapy in children. J Heart Lung Transplant. 2007;26(5):453-7.

6. Buck ML. The use of milrinone in infants and children. Pediatr Pharm [Internet]. 2003 Feb [cited 2015 Mar 7];9(2). Available from: www. medscape.com/viewarticle/450048. Registration required to access content.

7. Bishara T, Seto WT, Trope A, Parshuram CS. Use of milrinone in critically ill children. Can J Hosp Pharm. 2010;63(6):420-8.

8. Milrinone [product monograph]. In: Lexicomp [database on Internet]. Wolters Kluwer; (C) 1978-2016 [cited 2016 Sep 20]. Available from: http://online.lexi.com/lco/action/doc/retrieve/docid/pdh_f/129918 [accessed through institutional subscription]. Subscription required to access content.

9. Report page: CORR 2016 [Canadian Organ Replacement Register annual report]. Ottawa (ON): Canadian Institute for Health Information; 2016 [cited 2016 Sep 19]. Available from: https://www.cihi.ca/en/organreplacements/corr-annual-report

10. Trissel LA. Handbook on injectable drugs. 14th ed. Bethesda (MD): American Society of Health-System Pharmacists; 2006.

Ariel Xue, BScH, BScPharm, ACPR, is with Pharmacy Services, Alberta Health Services, Calgary, Alberta.

Deonne Dersch-Mills, BScPharm, ACPR, PharmD, is with Pharmacy Services, Alberta Health Services, Calgary, Alberta.

Clara Tsang, BScPharm, is with Pharmacy Services, Alberta Health Services, Calgary, Alberta.

Steven C Greenway, MSC, MD, FRCPC, is with the Departments of Paediatrics, of Cardiac Sciences, and of Biochemistry and Molecular Biology, University of Calgary, and is also with Alberta Health Services, Calgary, Alberta.

Competing interests: None declared.

Address correspondence to:

Dr Deonne Dersch-Mills

Inpatient Pharmacy Department

Alberta Children's Hospital

2888 Shaganappi Trail NW

Calgary AB T3B 6A8

e-mail: deonne.dersch-mills@ahs.ca

Funding: None received.

Acknowledgement: In addition to the literature cited, the authors would like to acknowledge the Cardiology Section at the Hospital for sick Children (Toronto, Ontario) for sharing that institution's guidelines for outpatient continuous inotropic therapy. 